\title{
Las señoritas de Avignon y el discurso crítico de la modernidad
}

\author{
MÉNDEZ BAIGES, Maite \\ Universidad de Granada, Granada, 2021 \\ ISBN: 978-84-338-6749-0
}

La racionalización formal y la aspiración a concebir la pintura a partir del modelo del signo hicieron del cubismo, como escribió T. J. Clark, «el tema del arte moderno» (1999: 175). No puede por tanto sorprender el que las obras señeras de Picasso sigan ocupando un lugar privilegiado en la discusión historiográfica sobre aquel, como de hecho lo muestran algunos ejemplos recientes entre nosotros. En una lista elaborada para Artforum en 2011, Manuel Borja-Villel no dudaba en señalar como uno de los acontecimientos culturales del año una exposición, Picasso: Guitars, 1912-14 (MoMA), que se ocupaba de su concepción de la pintura como una construcción lingüística. En 2017, el Reina Sofía conmemoraba los ochenta años de Guernica con la exposición Piedad y terror en Picasso, en la que T. J. Clark releía el cuadro en relación con la desaparición del espacio de la intimidad burguesa y la comunidad que la sostenía. Y poco después, Rocío Robles Tardío publicaba Informe Guernica (2019), un texto donde recorre la posthistoria del cuadro y estudia el papel que ha tenido la "gestión» en su conversión en icono. Nos llega ahora, finalmente, este estupendo libro de Maite Méndez Baiges, también sobre la posthistoria de otra obra clave, Las señoritas de Avignon, justamente aquella en que la narrativa moderna sobre el arte encontró a menudo su punto de partida. De ahí que, desde el título mismo, el libro asuma como tema "el discurso crítico de la modernidad", indisociables las interpretaciones del cuadro del debate sobre la modernidad misma: "...vamos a defender, además, que las lecturas posibles de esta obra en concreto están estrechamente ligadas a la consideración del propio arte moderno en su conjunto, dado que casi desde el momento de su ejecución fue considerada una de sus obras maestras" (2021: 19).

Con el propósito de explorar esa relación, Maite Méndez recorre con mimo la historia de la recepción del cuadro,
Maite Méndez Baiges

\section{Las señoritas de Avignon}

y el discurso crítico de la modernidad

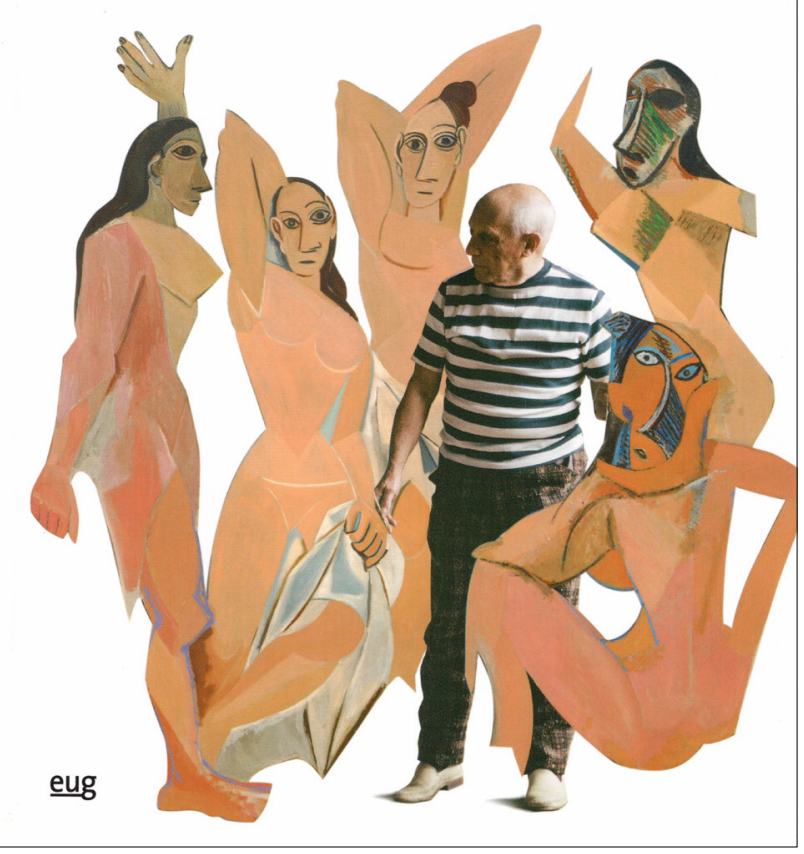

asumiendo una de las consecuencias de la vanguardia, la que Marcel Duchamp desarrollaba en «El proceso creativo». Esto es: que la obra no está "acabada» hasta que no se produce su recepción (2021: 21), o, como puede extraerse a partir de la noción benjaminiana de aura y de los desarrollos posteriores de la estética de la recepción, que la acumula-

Cómo citar este artículo: CABELLO, Gabriel, «MÉNDEZ BAIGES, Maite: Las señoritas de Avignon y el discurso crítico de la modernidad», Boletín de Arte-UMA, n. 42 , Departamento de Historia del Arte, Universidad de Málaga, 2021, pp. 309-311, ISSN: 0211-8483, e-ISSN: 2695-415X, DOI: http://dx.doi.org/10.24310/BoLArte.2021.vi42.13229 
ción de usos e interpretaciones de una obra, su posthistoria, forman parte de ella. A partir de una confusión inicial en parte estimulada por el propio Picasso, el libro recorre la estabilización de un discurso en torno a Las señoritas que confluye con la construcción del «relato ortodoxo de la modernidad» (2021: 21), el modernism, que Méndez considera formalista. De Salmon (1912) a Kahnweiler (1915) se irá fijando ese relato que entiende la pintura como "arte de superficie» y coherencia espacial, y que hará comenzar el cubismo en la figura en cuclillas de la derecha, con el corolario de atribuir un carácter sígnico, no icónico, a la pintura concebida como «una estructura» legible y no un «reflejo de la naturaleza». Esta será, afirma la autora, la lectura hegemónica moderna: «Entre 1939 y 1972 la perspectiva usada para analizar Las señoritas siguió a grandes rasgos la senda marcada por Kahnweiler, la obra como la solución a un problema de naturaleza enteramente pictórica, y, por tanto, como obra protocubista; y así es como la tratarían a continuación autores tan relevantes como Alfred Barr Jr., el primer director del MoMA de Nueva York, y John Golding, una de las máximas autoridades en pintura cubista» (2021: 44). Barr (1939 y 1946) pudo así configurar un discurso donde la influencia del «arte negro» era contemplada como estrictamente formal.

La historia de la posterior recepción de Las señoritas será la del derribo de ese discurso formalista, cuyas primeras grietas emergerán junto al problema iconológico asociado al motivo del «recuerdo del burdel de Barcelona» de que Picasso habló a Zervos. Con el antecedente de John Nash (1970), será la publicación de «El burdel filosófico» (1972) de Leo Steinberg la que sustituya la pregunta formal por el reto al espectador que supone lo «terrible» de las mujeres; de los «problemas desnudos» (de la pintura) se pasará a los «desnudos problemáticos» (de las mujeres). El espectador sexuado, implícitamente masculino y amenazado por la peligrosa sexualidad de las prostitutas, pasaba así a ser prácticamente parte de la obra, toda vez que, en la versión final, las figuras giradas 90 grados lo interpelan con sus rostros demoníacos y atractivos, como una mirada de Medusa que impide el distanciamiento del pintor o del esteta. El estudiante de medicina del proyecto original es ahora el espectador, protagonista de un encuentro traumático.

El texto de Steinberg cambió las reglas del juego, abriendo el paso a las lecturas contextualistas: tanto a las psicobiográficas de Wiliam Rubin (1984 y 1994), quien re- dujo el sentido a la biografía afectiva y sexual de Picasso, o Mary Mathews Gedo (1980) y Lydie Pearl (2001), quienes indagaron en la ambivalencia de su trato con las mujeres y en la transformación de la identidad de Picasso percibida en el proceso del cuadro, como a la culturalista de Natasha Staller (2011), centrada en la incidencia del universo de las imágenes religiosas malagueñas. Pero con ello emergía un nuevo problema: el de la pérdida de la universalidad del gesto de rebelión de Picasso. Desde la New Art History, R. E. Krauss (1981) o Yves-Alain Bois (2001) insistieron en que la reducción del sentido a lo psicobiográfico bloqueaba ese gesto de rebelión, al que, eso sí, ahora debía incorporarse un fundamento libidinal: el "efecto medusa» del cuadro, que implicaba que el estudio de los códigos de significación no era separable del espectador, determinado desde el punto de vista social y de género. Por más que quisiera retener, lejos de la psicobiografía, el carácter universal de esa rebelión, la crítica iba en adelante a partir del "conocimiento situado", dando voz a los «sujetos subalternos» concernidos, las mujeres y los africanos, que debían dejar de ser un «otro» invisible, neutralizado como un terror exorcizado. Las señoritas seguían ocupando el centro del discurso moderno, pero ahora por una suerte de vía negativa: como señalaba Hal Foster, la modernidad, falocéntrica y eurocéntrica, había convertido una imagen de sus propias crisis en uno de sus monumentos.

Tomando como centro la posibilidad de una espectadora femenina, Carol Duncan (1989) o Anna C. Chave (1994) estudiaron cómo los cuerpos femeninos sexualizados masculinizan el museo y neutralizan el temor a la independencia femenina en un tiempo en que la hegemonía masculina y sus modos de percepción empiezan a tambalearse. Operación de neutralización que se extiende a lo africano, sobrecargado en la imaginación colonial con una sexualidad salvaje y descontrolada. En relación con su visita a Trocadéro en 1907, Picasso había reconocido que el art nègre significó para él algo espiritual, más mágico que formal, y los trabajos de William Rubin mostraron que las máscaras aducidas no pudieron servirle de modelo formal. De este modo, ya en el siglo XXI aparecerán trabajos centrados en la relación entre la prostitución y el imaginario colonial de lo primitivo, ya sea como «contracanon» con el que Picasso se identifica (Leighten, 2001), o como muestra de los prejuicios coloniales sobre «el otro», patológico y amenazante (David Lomas, 2001). Picasso habría así despojado a lo africano de su peligro in- 
herente, al entender su arte como fetiche de raíz mística y no como producto cultural hecho por seres humanos (Gikandi, 2003). Una objeción que, sin embargo, no podría haberse hecho del mismo modo al formalismo de Barr, que entendía las máscaras como artefactos artísticos, en lo que Méndez señala como «una de las muchas paradojas de la posmodernidad» (2021: 140).

Quizá hubiese merecido la pena que el texto se detuviese algo en la naturaleza de esas «paradojas», del mismo modo que podría haberlo hecho en desbrozar algo más dos conceptos de forma, el kantiano del modernism y el, por así decirlo, mallarmeano de la lingüística estructural que a veces se solapan en el texto y que distinguió Y.-A. Bois (1990: 95-97). Pero ciertamente ambos problemas están señalados por la autora, y puede que excavar más en ellos hubiera hecho que el recorrido por la historia de la recepción de Las señoritas perdiera algo de la viveza que el libro mantiene en todo momento. Una viveza que permite asimismo pasar con naturalidad a las exposiciones como parte de esta historia de la recepción del cuadro: desde la disposición con que en 2019 el MOMA con obras de Faith Ringgold y de Louise Bourgois, haciéndose eco de la necesidad de escuchar las voces subalternas, pasando por las exposiciones de Picasso en Dakar (1972) y Sudáfrica (2006), en las que el arte africano seguía apareciendo como anónimo y a menudo sin cronología, apenas como musa del pintor, y hasta la exposición de 2017 en el Museo del Quai Branly, Picasso primitivo, donde, como quiso a comienzos del siglo XX Carl Einstein, el africano se consideraba por fin como arte de pleno derecho y con su propia historia, no como mero efecto del fetichismo y el ritual.

La gran cantidad de información que el trabajo de Maite Méndez proporciona no podía, finalmente, dejar de lado la «impertinencia anacrónica» (Didi-Huberman) con que los propios artistas han dialogado con Las señoritas. El capítulo final recorre de modo delicioso esos diálogos que desde el pop y su sexualización del espectador al apropiacionismo y su desestabilización de las nociones de autoría y original, desembocarán en la exploración de la posibilidad de otras miradas. Como la de Faith Ringgold, en cuyo Picasso's Studio (1991) el propio artista aparece pintando a una Willia María, la protagonista africana de las story quilts, que, con Las señoritas al fondo, escucha las voces de las máscaras africanas que la rodean. O como las versiones queer de Rafael Agredano (1994), que desestabilizan la mirada masculina heterosexual. Seguramente es solo ahora cuando se reconocerá plenamente al espectador el papel de cómplice de la escena, al precio, eso sí, de movilizarlo, cuando no, como harán Francis Alÿs o Rogelio López Cuenca y Elio Vega, de forzarlo a la irreverencia. Un precio que debería también pagar con gusto el historiador del arte moderno en cuyas manos caiga este trabajo de historia de la recepción con el que será difícil no contar en adelante.

\section{Bibliografía}

BOIS, Yve-Alain (1990), «Kahnweiler's Lessson», en Painting as Model, MIT, Cambridge (Mass.), pp. 65-97.

BORJA-VILLEL, Manuel (2011), «Best of 2011», Artforum, vol. 50, n. ${ }^{4}$, diciembre 2011. <https://www.artforum.com/print/201110/manuel-borja-villel-29555>.

CLARK, T. J. (1999), Farewell to an Idea: Episodes from a History of Modernism, Yale UP, New Haven y Londres.

CLARK, T. J. (2017), Piedad y terror en Picasso. El camino a Guernica, MNCARS, Madrid.

ROBLES TARDíO, Rocío (2019), Informe Guernica. Sobre el lienzo de Picasso y su imagen, Ediciones Asimétricas, Madrid. 